\title{
EDITORIAL
}

\section{NO A LAS GUERRAS}

\author{
Cristina Pérez Andrés \\ Comité de redacción de la Revista Española de Salud Pública.
}

El Boletín técnico de la Dirección General de Sanidad hizo su aparición en enero del año 1926, bajo la dictadura que Miguel Primo de Rivera instaurara el 13 de septiembre de 1923. A pesar de este condicionante continuaba entonces en el país la llamada «Edad de Plata de la cultura española «, que transcurrió desde 1868 hasta $1936^{1,2}$, año del golpe militar que puso fin a la Segunda República. La denominación «Edad de Plata« se justifica porque durante ella tuvo lugar un importante impulso al desarrollo de la cultura en general y de las ciencias y la tecnología en particular, así como una vocación europeísta por parte de los pensadores y de los responsables de las instituciones, para que España no se quedara atrasada en relación al resto de los países. Hecho destacable de esta Edad de plata fue la fundación en 1876 de la Institución Libre de Enseñanza por un grupo de profesores universitarios seguidores del pensamiento krausista ${ }^{3}$, los cuales habían sido expulsados de la Universidad por defender la libertad de cátedra, el laicismo y el pensamiento científico. Desde ella Giner de los Ríos inculcaba la idea básica de la educación como fundamento de todo programa de reforma social y se propició el renacimiento de la ciencia española, sobre todo a nivel de la biología y la medicina, pero también en otras materias como química, física y ciencias exactas.
En enero de 1907 el Ministerio de Instrucción Pública y Bellas Artes creó la Junta para la Ampliación de Estudios e Investigaciones Científicas (JAE) ${ }^{4,5}$ con el objetivo de proceder a una reforma del sistema educativo que incluyera la función investigadora de la Universidad. Desde sus inicios estuvo presidida por Santiago Ramón y Cajal, hasta su muerte el 17 de octubre de 1934, siendo entonces sustituido por Ignacio Bolívar, entomólogo. La secretaría de la Junta estuvo ocupada por José Castillejo, procedente también de la Institución Libre de Enseñanza y licenciado en Derecho y Filosofía y Letras.

Hombres y mujeres de ciencias y letras se formaron en las instituciones creadas por la JAE, para más tarde ser los encargados de poner en marcha el programa renovador de la ciencia y la cultura españolas. Bajo el impulso de la JAE se crearon el Centro de Estudios Históricos, el Instituto Nacional de Ciencias Físicas y Naturales, la Asociación de laboratorios, la Escuela Española en Roma de Arqueología e Historia, el Laboratorio Seminario Matemático ${ }^{6}$, el Instituto Escuela de Madrid, la Residencia de Estudiantes y el Patronato de Estudiantes. La JAE también financió los estudios en el extranjero de numerosos estudiantes, profesores e investigadores. Uno de los hechos más destacable de aquellos tiempos fue la concesión del premio Nóbel de literatura a 
José Echegaray en 1904 y el Premio Nóbel de Fisiología y Medicina a Santiago Ramón y Cajal en 1906. Cincuenta años más tarde lo obtendría Severo Ochoa, quien también trabajó en los laboratorios de la Residencia de Estudiantes junto a Juan Negrín.

Cuando se iniciaba en España lo que algunos consideran un nuevo siglo de oro tuvo lugar el golpe de estado de Franco contra la segunda República instaurada como resultado de las elecciones generales de abril de 1921. El 9 de mayo de 1938 la JAE fue suprimida y sus instituciones cerradas o requisadas por los golpistas. Muchas de las personas que en ellas trabajaban se exilaron, interrumpiéndose así toda la labor de investigación, estudio y docencia ${ }^{7}$. Tras la guerra civil que siguió al golpe fascista y a la dictadura que se mantuvo durante cuatro décadas se malograron los objetivos tan largamente perseguidos.

Como ya vimos en el número anterior, el Saludo y Programa publicado en el primer número del Boletín Técnico de la Dirección General de Sanidad,9, firmado por Francisco Murillo, declaraba que el objetivo principal de la publicación era comunicar los resultados de las investigaciones realizadas en España, así como difundir documentos científicos extranjeros. En 1932 el Boletín pasó a llamarse Revista de Sanidad e Higiene Pública y en ella se constituyó un comité de redacción cuya composición se reproduce en este número de la revista ${ }^{10}$. Tras la guerra civil el destino de la mayoría de los miembros de este comité fue el exilio y los que se quedaron en España fueron destituidos de sus cargos y expulsados de sus cátedras ${ }^{7,11}$.

La revisión de los índices del Boletín Técnico de la Dirección General de Sanidad y de la Revista de Sanidad e Higiene Pública hasta el año 1935 permite entender la claridad que del objetivo del mismo tenían sus responsables. En los títulos de los trabajos publicados se refleja la preocupación de autores y editores por las condiciones socio- sanitarias del país y de la salud de la población, siendo las materias más frecuentemente tratadas las enfermedades infecciosas como la tuberculosis, la sífilis, el tracoma, la salmonellosis, pero también la alimentación como factor primordial para una buena salud. Entre los editores de la publicación existía una ética que se refleja en textos como el que reprodujimos en el número anterior sobre las patentes de los medicamentos $^{12}$, o en la renuncia a financiarse por dinero procedente de la publicidad, postura que se interrumpió en el primer número de $1938^{13}$. Sin embargo, en el período que precedió incluso a la victoria franquista llama la atención el contenido de los textos de esta publicación, que era sanitaria y no política. En la primera página del primer número de 1938 junto a una fotografía del dictador figura el siguiente título: Al Excmo Sr General D Francisco Franco, Jefe del estado Español ${ }^{15}$. El contenido es sencillamente irreproducible. A continuación un editorial ${ }^{15}$ que insiste en el espíritu del texto anterior en el que se agradece la oportunidad que han tenido de salvar la patria de las hordas de rojos y marxistas, vocabulario que se repite en la mayor parte de los trabajos de los 12 números, siguiendo con la inclusión cada pocas páginas de anuncios que contienen vivas a Franco y a su dictadura, de tal forma que resulta escalofriante tener estos números en las manos. Los títulos de los artículos originales están relacionados con la contienda, algo que en principio no tiene por qué extrañar, dada la influencia de cualquier guerra en la salud de las personas y de la sociedad, en los abastecimientos de alimentos y agua, en la prestación de los servicios, etcétera. Pero en los 12 números que se publicaron durante los años 1938 y 1939, la revista que fue creada con objetivos científicos se convirtió en un vehículo de propaganda fascista y, lo que es peor, el contenido de los artículos que componen estos ejemplares, que no dejan de llamarse artículos originales, como si de artículos científicos se tratara, está lleno de insultos, ofensas e ignominias hacia las personas que habían preparado el desarrollo científico 
y cultural de España durante muchos años de trabajo y dedicación, planificación y financiación de estancias en el extranjero, a través de la Junta de Ampliación de Estudios, para los estudiantes y estudiosos que más tarde debían ocupar los puestos de responsabilidad en la educación y formación de las generaciones futuras. Calificativos espeluznantes dirigidos a personas que desde el último tercio del siglo XIX tuvieron claro que España podía y debía encontrarse entre los países que ponían por delante el progreso, el desarrollo y la cultura para beneficio de la población y como patrimonio de la misma. Santiago Ramón y Cajal, al que el número 4 de 1930 el Boletín Técnico de la Dirección General de Sanidad le dedicó su sección de Las grandes figuras de la Sanidad ${ }^{16,17}$ tuvo la suerte de morir a tiempo de no asistir a la rabiosa destrucción de las instituciones en las que tanto colaboró como fundador y director.

Nada de ello se puede ya evitar. Sin embargo, ahora que tengo conocimiento de ello, considero de justicia que en las páginas de la misma revista para la que trabajaron antes del golpe militar las personas que luego serían insultadas desde ella y víctimas de una feroz dictadura, haya un lugar para su recuerdo, para manifestar el agradecimiento que muchos sentimos hacia la labor que acometieron durante el primer tercio del siglo $\mathrm{XX}$, y para dejar constancia de que somos conscientes de que el golpe militar de 1936 interrumpió para siempre la labor cultural y científica de muchos de ellos, pero que el desarrollo profesional en el exilio de los que tuvieron mejor suerte no ha dejado de beneficiarnos, porque los conocimientos que como investigadores lograron en los países que los acogieron son patrimonio de la humanidad.

Posiblemente el mejor homenaje que se le puede rendir hoy a los exilados españoles de la guerra civil, desde la misma revista que los vencedores utilizaron para insultarles, sea reproducir sus publicaciones, para dejar constancia de que su trabajo no consistió en la mentiras vertidas sobre ellos sino, muy al contrario, en sabios precedentes de lo que en la actualidad constituye el hacer de la epidemiología y la medicina contemporánea. Como ejemplo de ello reproducimos el artículo de Marcelino Pascua Aumenta la diabe$t e s^{18}$, en el que ofrece cifras relativas a esta enfermedad no sólo de España sino también de otros países y aventura hipótesis sobre su patogenia que hoy persisten.

Ello con el deseo ¿por qué no? de que las guerras acaben en todo el planeta y de que ello contribuya a la superación de la pobreza y en ningún lugar del mundo nadie tenga que volver a exilarse por motivos políticos ni económicos.

\section{BIBLIOGRAFÍA}

1. Archivo virtual de la Edad de Plata (1868-1936. Disponible en: http://www.archivovirtual.org/primera.htm

2. La Edad de Plata 1890-1936. Disponible en: http://www.ucm.es/info/hcontemp/leoc/ciencia\%20en\%20madrid.htm\#LA\%20EDAD\%20DE \%20PLATA:\%201890-1936

3. La Institución Libre de Enseñanza. Disponible en: http://www.almendron.com/historia/contemporanea/krausismo/krausismo.htm

4. Antecedentes del CSIC: La JAE. Disponible en: http://www.csic.es/historia.do?id=historia_JAE\&1 engua $=$ es

5. La Junta de Ampliación de Estudios, 1907-1936. Disponible en: www.ucm.es/info/hcontemp/ madrid/ciencia.htm

6. González Redondo F. La actividad del Laboratorio Seminario Matemático de la Junta para Ampliación de Estudios durante la Guerra Civil. La gaceta 2001; vol 4: 675-686. Disponible en: http://www. divulgamat.net/weborriak/historia/Mirando/miran doindex.asp

7. García Camarero E. La ciencia española en el exilio de 1939. Madrid: Tauros ediciones; 1978.p.189243. 
8. Murillo F. Saludo y Programa. Boletín técnico de la dirección general de sanidad 1926; 1;5-7.

9. Murillo F. Saludo y Programa. Rev Esp Salud Pública 2006; 80: 183-184.

10. Comité de redacción de la Revista de sanidad e higiene pública en 1932. Rev San Hig Pública 1932; 7.

11. Comité de redacción de la Revista de sanidad e higiene pública en 1932. Rev Esp Salud Pública 2006; 80.

12. Biografías de españoles exiliados. Disponible en: http://www.exiliados.org/paginas/Conservar_mem oria/Biografias_A.htm
13. La ética y las patentes. Boletín técnico de la dirección General de sanidad 1927; 2 y Rev Esp Salud Pública 2006; 80: 193-6.

14. Revista de Sanidad e Higiene Pública 1938; 13.

15. Rev San Hig Pública 1938; 13: 1

16. Editorial. Rev San Hig Pública 1938; 13: 3-5.

17. Las grandes figuras de la sanidad. Don Santiago Ramón y Cajal. Boletín técnico de la dirección General de sanidad 1930; 9;349-50. y Rev Esp Salud Pública 2006; 80: 189-90.

18. Pascua M. Aumenta la diabetes. Rev San Hig Pública 1935; 14:153-63. 